\title{
Bucher's Broom and Selenium Improve Lipedema: A Retrospective Case Study
}

\author{
Nourollahi $\mathrm{S}^{1,2}$, Mondry $\mathrm{TE}^{3}$ and Herbst $\mathrm{KL}^{1,2 *}$
}

${ }^{1}$ Departments of Medicine, University of California, San Diego, USA

'Veteran's Affairs San Diego Healthcare System, San Diego, California, USA

${ }^{3}$ New Horizons Physical Therapy, Encinitas, California, USA

\begin{abstract}
Background: Butcher's broom plant extract has been reported to improve lymphatic flow and the trace mineral, selenium, has been shown to improve lymphedema. This retrospective case study examines the effectiveness of Butcher's broom in conjunction with selenium to decrease limb volume of a patient with lipedema, a common fat distribution disorder with excess adipose tissue fluid.

Methods: Selenium (400 $\mathrm{mcg}$ ) was initiated 6 days prior to limb volume evaluation utilizing perometry. The patient underwent physical therapy that consisted of manual lymph drainage (MLD) with Histological Variable Manual Technique (HIVAMAT), and compression bandaging. Butcher's broom (one gram daily) was added on day 95 of treatment in addition to selenium and both were continued through day 293 (end of study).

Results: Total volume reduction over the study period for the left and right upper extremities and left and right lower extremities was $525 \mathrm{ml}$ and $225 \mathrm{ml}(p<0.05)$, and $1769 \mathrm{ml}$ and $1614 \mathrm{ml}(p<0.0001)$, respectively. The total percent volume reduction during the time period when MLD with HIVAMAT and compression bandaging were performed for the left and right legs was 70.6 and $79.0 \%$, respectively. In the absence of compression bandaging, the left and right arms lost 21.2 and $10 \%$ of initial volumes, respectively at the 6 month follow-up visit. During the latter part of the study when the patient was performing a home maintenance program, at which time selenium and Butcher's broom were continued, the left and right lower extremities decreased an additional 29.4 and $20.9 \%$ of initial volumes, respectively, despite a lack of exercise due to a foot injury during the last 46 days.
\end{abstract}

Conclusion: Butcher's broom and selenium may offer new tools in conjunction with physical therapy to improve swelling and pain associated with lipedema.

Keywords: Lipedema; Lipoedema; Lipolymphedema; Butcher's broom; Selenium

\section{Introduction}

Lipedema was first named in 1940 by Drs. Allen and Hines at the Mayo Clinic $[1,2]$ though there are case reports in the literature dating back to the 1800s that suggest lipedema has been around much longer $[3,4]$. A distinct disorder from lymphedema due to the general lack of involvement of the feet or hands, there is an increase in adipose tissue in lipedema, usually in the hips, buttocks, legs and arms that cannot be effectively reduced by diet or exercise [5]; the physiology includes interstitial edema of increased adipose tissue triggered by a disturbance of blood capillary permeability [6]. Lymphatic fluid flow in lipedema is increased early but later becomes depressed and aneurysms form [7] if left untreated, lipedema can progress to lymphedema, a condition referred to as lipolymphedema, where the excess lymph fluid can worsen the lipedema in both extent and amount [8].

Lipedema, although reported as rare, [9] is a common fat distribution disorder $[9,10]$ reported to affect between $11 \%[9,10]$ to $39 \%$ of the female population [11]. The clinical signs and symptoms of lipedema include unregulated growth of nodular (and often times painful) fatty deposits on the lower body and arms which cannot be lost with diet or exercise, and when palpated feel like beans in a bag [12]. Other clinical manifestations include edema, easy bruising, and an asymmetry in body shape, where the lower half of the body is much larger in subcutaneous adipose tissue volume as compared to the upper body [13]. Lipomas may also be found in the adipose tissue as isolated or clustered masses which are non-encapsulated [12,14]. Lipedema primarily affects women, and is usually diagnosed at puberty or by the third decade [15]. Lipedema can be exacerbated or incited to develop by pregnancy and childbirth or menopause [16]. The development of fatty tissue deposits or lipomas can reduce mobility. This induces patients with lipedema to seek medical care, yet this patient population may go undiagnosed for years. Many patients with lipedema self-diagnose and bring the concept of lipedema to the attention of their healthcare provider.

The diagnosis of lipedema must be made clinically as there are no biological markers. Even though lipedema can be an inherited condition, likely autosomal dominant passing from mother or father to daughter [15], there are currently no known associated genes.

Current treatment of the fluid component of lipedema (and lipolymphedema) includes complete decongestive therapy (CDT) consisting of MLD, compression bandaging, exercise, meticulous skin care, and patient education on self-management of lymphedema. Ultimately, patients are fitted with a compression garment to inhibit the return of fluid to the adipose tissue [17]. Improvement in limb volume

*Corresponding author: Karen L Herbst, Departments of Medicine, University of California, San Diego, Veteran's Affairs San Diego Healthcare System, San Diego, California, USA, Tel: 858-552-8585 (7384); Fax: 858-642-6242; E-mail: kaherbst@gmail.com

Received May 20, 2013; Accepted June 01, 2013; Published June 04, 2013

Citation: Nourollahi S, Mondry TE, Herbst KL (2013) Bucher's Broom and Selenium Improve Lipedema: A Retrospective Case Study. Altern Integ Med 2: 119. doi:10.4172/2327-5162.1000119

Copyright: (c) 2013 Nourollahi S, et al. This is an open-access article distributed under the terms of the Creative Commons Attribution License, which permits unrestricted use, distribution, and reproduction in any medium, provided the original author and source are credited. 
by CDT in a patient with lipedema has been demonstrated, [18] with a reduction of circumference of approximately $10 \%$ and a decrease in volume of up to three liters per leg $[19,20]$. Compression garments are worn to maintain the decrease in fluid achieved with CDT [13].

To support CDT-induced reduction in fluid in the lipedema fat, we investigated supplements that improve lymphedema. Selenium is a trace mineral which has been shown to reduce lymphedema by lowering fluid retention rates within the body $[19,20]$. Butcher's broom, a powdered extract in capsule form derived from the plant, Ruscus aculeatus, has been shown to bind as an agonist to alpha adrenergic receptors on lymph cells, increasing lymph fluid movement within lymph vessels $[21,22]$. There are no published data on the use of selenium or Butcher's broom in lipedema. In this case report, these two supplements were used to support the reduction in limb volume achieved with CDT for a patient with lipedema. Despite a lack of exercise after CDT, our patient continued to lose volume and weight while taking selenium and Butcher's broom.

\section{Materials and Methods}

This case report was considered to be exempt by the University of California, San Diego (UCSD) Human Research and Protection Program. The patient with lipedema in this case report was cared for at the UCSD Medical Offices South and at New Horizons Physical Therapy in San Diego, California, USA. Informed consent was obtained from the patient for publication of this case report.

\section{Limb volume}

Limb volume was assessed utilizing a vertically oriented perometer (Pero-System Meßgeräte GmbHModel Type $1000 \mathrm{M}$ ). A perometer is an optoelectronic limb volumeter that utilizes infrared beams to assess limb volume in milliliters $(\mathrm{ml})$ and has been validated against the tape measure method with a high test-retest reliability and acceptable measurement error [21]. Limb volume was assessed at the initial evaluation, at the end of each week of treatment, and one-month post treatment. Reassessments were also performed at three and six months post treatment.

\section{Physical therapy}

The physical therapy treatment provided to the patient consisted of MLD with HIVAMAT, skin care, compression bandaging, and compression garments. Manual lymph drainage is a manual technique that is utilized to increase lymphatic flow and therefore decrease stagnate lymph fluid. Skin care consisted of inspection of the skin for any signs of trauma or infection, as well as moisturizing the skin. The HIVAMAT (HIVAMAT 200 Personal; Activiva, Pulheim, GM) is device that creates a deep oscillation within the tissue by an intermittent electrostatic field. It has been used for treatment of pain and swelling in secondary lymphedema of the breast [22,23] and wound healing [24]. Compression bandaging is a multiple layer short stretch compression bandage that is applied over the length of the limb and worn 24 hours per day during the treatment phase. The compression garments were utilized after the completion of compression bandaging during the treatment phase, as well as during the maintenance phase; the garments were worn during waking hours only.

\section{Oral supplements to lessen fluid retention}

The patient was started on selenium ( $400 \mathrm{mcg}$ daily) 6 days prior to physical therapy and was continued to the end of study (day 293). The patient was also started on Butcher's broom (1 gram daily) on day 95.

\section{Statistics}

Changes in average upper and lower extremity volume were assessed by repeated measures ANOVA; Tukey's multiple comparison tests was used to compare limb volumes versus baseline. Spearman correlation was used to compare body weight to limb volume change. A $\mathrm{p}$ value $<0.05$ was considered significant.

\section{Case Report}

The patient is a 67 year old female who presented to clinic complaining of increasing leg size (swelling). The patient reported discomfort in her lower legs that included pain with sitting, though the pain would lessen with exercise. She also complained of problems with balance, secondary to the swelling in her legs. On review of systems, the patient stated she felt fatigued with flu-like symptoms and felt thirsty all the time. Additional symptoms included vertigo, headaches, hearing loss, not sleeping well at night, difficulty swallowing, fluctuations in body temperature, and bloating. General abdominal pain had subsided when she began a protein drink that contained polyphenols. She also complained of frequent urination during the day, felt she retained water during the day, and had nocturia. The patient reported that muscle and joint aches were common, especially in the lower legs. It was noted that her skin bruised easily in lipoma clusters, and she had itching and burning sensations.

The patients exercise regimen included Pilates, weight training and walking. The patient continued with her exercise regimen throughout most the treatment phase until she injured her foot on day 247. She wore prescription grade $(30-40 \mathrm{mmHg}$ ) thigh high compression stockings on a daily basis.

The patient's past medical history (and medications in brackets) included a diagnosis of Celiac disease (gluten allergy) [digestive enzymes and probiotics], diabetes type 2 [pioglitazone], dyslipidemia [atorvastatin], and hypertension [verapamil and lisinopril]. The patient also reported that she was on an aspirin regimen for primary prevention of cardiovascular disease.

\section{Physical examination of body fat and skin}

Presentation of the head and neck were normal. There was nodular fat that upon palpation felt like beans in a bag. For the purpose of this article this type of nodular fat will be referred to as lipedema fat. The patient presented with lipedema fat from the wrists extending up the arms with the left wrist being larger than the right, and both with small lipomas. The patient presented with enlarged lipedema fat around the medial cubital areas extending up to the acromion with normal fat medially along the clavicle to the sternum. Veins were easily visible under the skin on the arms and appeared enlarged. The hands were normal with minimal to no fat and easily visible veins. Lipedema fat was present on the upper chest, abdomen, hips and buttocks. The thighs had lipedema fat throughout the anterior and posterior aspects with a thinning of the skin on the superior-medial aspect of the thighs; varicose veins were easily visible under the skin. There were raised areas of thin skin in a bubble pattern all over the thighs and indentations with a mattress-like appearance consistent with stage II lipedema. The knees had tender lipedema fat pads that extended medially between the knees. There were pockets of fat on the ankles bilateral with enlarged medial and lateral perimalleolar fat pads, with the right side more affected than the left. The initial diagnosis was lipedema stage II with lipolymphedema. There was the possibility of the lipedema being induced and/or exacerbated by thiazolidinedione use, as these drugs 
are known to cause fluid retention and peripheral adipose tissue growth $[25,26]$.

\section{Management and outcome}

The patient was prescribed MLD to decongest lymphatics and encourage movement of lymph, compression garments for support of vasculature (blood and lymph), skin brushing to encourage blood flow in the skin and movement of lymph into initial lymphatics in the skin, mechanical movement of lymph through exercise, and maintaining normal blood and lymphatic structure though diet and polyphenols.

The main oral treatment prescribed at this visit was selenium, a trace mineral that has been shown to decrease edema in tissues and reduce the incidence of erysipelas skin infections in patients with chronic lymphedema $[27,28]$, with the goal being to decrease pre-lymph fluid in the tissue and therefore adipose tissue growth.

The patient underwent an initial evaluation of limb perometry and digital photography of bilateral upper and lower extremities (Figures 1 and 2). The patient presented with a volume of $2455 \mathrm{ml}$ for the left upper extremity, and $2254 \mathrm{ml}$ for the right upper extremity (Figures 1 and 3). The patient also presented with a volume of $8593 \mathrm{ml}$ for the left lower extremity, and $8490 \mathrm{ml}$ for the right lower extremity (Figures 2 and 3).

The physical therapist diagnosed the patient with moderate, stage II lipolymphedema of bilateral upper extremities, and severe, stage II lipolymphedema of bilateral lower extremities. The patient was prescribed physical therapy to include MLD, skin care, HIVAMAT, compression bandaging and therapeutic exercise 5 times a week for 1-4 weeks for each limb, with weekly reassessment of volume measures.

The patient underwent physical therapy 4-5 times per week for 6 weeks, during which time she continued her selenium. The patient received MLD with HIVAMAT, and compression bandaging for three weeks for the right lower extremity, and one week for the left lower

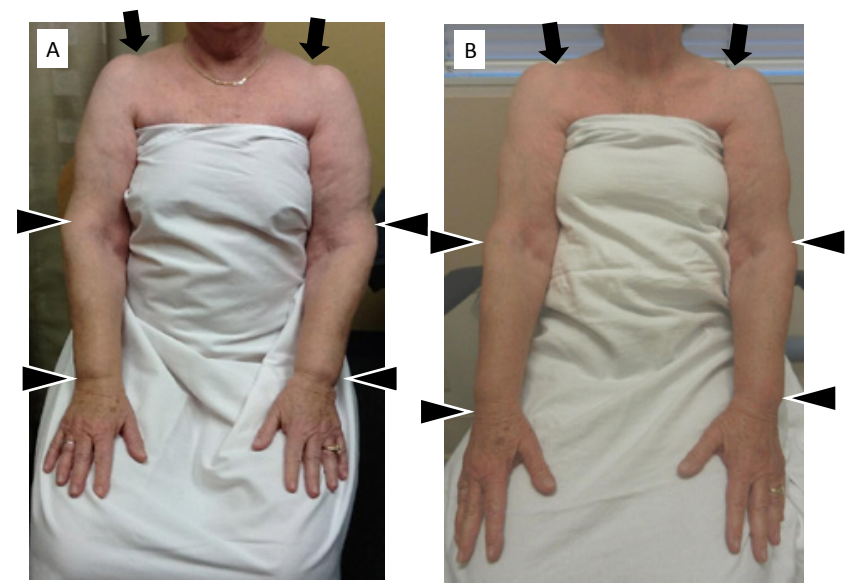

Figure 1: Photograph of patient's bilateral upper extremities pre and posttreatment. A) Patient's upper extremities 6 days after initiation of selenium and before physical therapy. Note the indentations in the skin and fat from the bra straps (arrows), and the enlarged fat deposits in the cubital areas (upper arrowheads), and the cuffs of fat at the wrists (lower arrowheads) with a lack of increased fat on the hands. B) Patient's six month reassessment post treatment on the last day of perometry measurement (day 293) while taking selenium, Butcher's broom and off pioglitazone. Note the reduction in fat in the cubital areas (upper arrowheads) and complete absence of the cuff of fat at the wrist on the right arm (lower arrowhead).
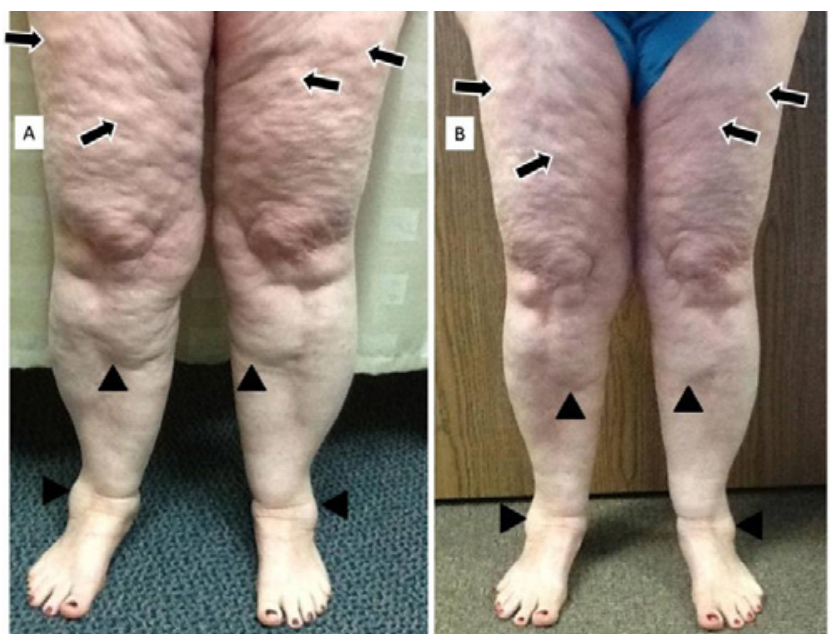

Figure 2: Photograph of patient's lower extremities pre and post- treatment A) Patient's lower extremities 6 days after initiation of selenium and before physical therapy. Note the raised areas of thin skin in a bubble pattern all over the thighs (some denoted by arrows) and the fat pads on the anterior shins below the knees as well as the pockets of fat on the lateral malleoli (arrowheads). Note also the lack of increased fat on the foot. B) Patient's six month reassessment post treatment and on the last day of perometry measurement (day 293) while taking selenium, Butcher's broom and of pioglitazone. Note that there are fewer raised areas of thin skin in a bubble pattern on the thighs, and that the fat pads below the knee and around the malleoli appear decreased, but are not absent.

extremity. The patient did not undergo compression bandaging of her upper extremities secondary to reports of pain after the first visit of compression bandaging of the left upper extremity but did undergo MLD with HIVAMAT for bilateral upper extremities for four visits each limb.

Volume measurements of limbs were reassessed after the first week of treatment for the left lower extremity measuring $2466 \mathrm{ml}$ in volume for the left upper extremity, and $2254 \mathrm{ml}$ in volume for the right upper extremity, both unchanged from previous. The left lower extremity measured $8023 \mathrm{ml}$ and the right lower extremity $8065 \mathrm{ml}$, representing a $570 \mathrm{ml}$ and $425 \mathrm{ml}$ decrease, respectively, or a $6.6 \%$ and $5.0 \%$ change in volume (Figure 3 ). This changed the diagnosis to moderate, stage II lipolymphedema of bilateral lower extremities. The patient was measured and fitted with a compression garment for the left lower extremity.

The patient's second week of physical therapy consisted of right lower extremity treatment. The reassessment by perometry at the end of the second week revealed the left upper extremity had a volume of 2309 $\mathrm{ml}$ and the right upper extremity had a volume of $2208 \mathrm{ml}$, representing a decrease of $157 \mathrm{ml}$ in the left upper extremity and $46 \mathrm{ml}$ in the right upper extremity, or a $6.3 \%$ and $2.0 \%$ change in volume, respectively, compared to the volumes noted during the initial evaluation (Figure 3 ). The patient presented with $7604 \mathrm{ml}$ in the left lower extremity and 7817 $\mathrm{ml}$ for the right lower extremity, representing a $989 \mathrm{ml}$ decrease in the left lower extremity and $673 \mathrm{ml}$ decrease in the right lower extremity, or a $11.5 \%$ and $7.9 \%$ respective decrease as compared to the initial evaluation. The patient was measured and fitted with a compression garment for the right lower extremity at that time.

The patient proceeded with the third week of treatment for the left upper extremity. Again, compression bandaging was not tolerated; therefore MLD and HIVAMAT were not performed. The volume 

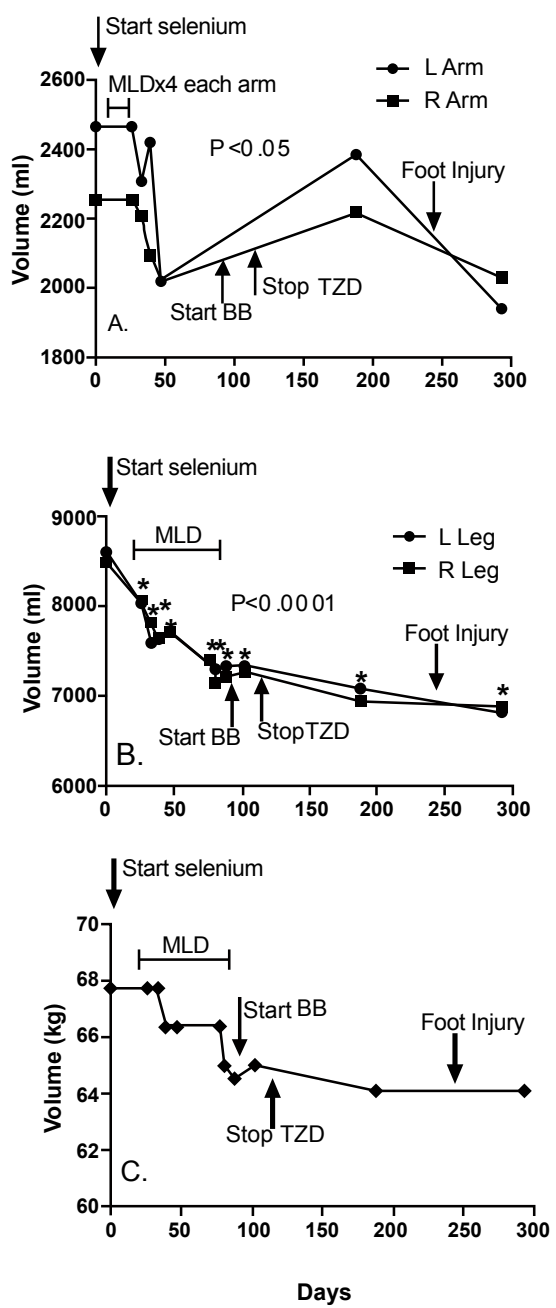

Figure 3: Volume measurements of the upper and lower extremities and total body weight during the time of perometry measurements, pre and post- treatment. A) Volume measurement of the arms from time zero of initial perometry measurement prior to initiation of physical therapy to the end of the study period (6 month assessment [day 293]). Noted on the graph are times of initiation of selenium (actual start was 6 days prior to time zero), physical therapy which included manual lymph drainage (MLD), start of Butcher's broom (BB), discontinuation of the thiazolidinedione (TZD) pioglitazone and the foot injury that prevented the patient from exercising. Decrease in volume from time 0 to 293 days was significant (P-value on graph). B) Volume measurement in the lower extremities from time zero to end of study. The decrease in volume from time 0 to 293 days was significant (P-value on graph). Notations as in $A .{ }^{*} P<0.05$ versus time $=0 . C$ ) Weight measurements from time zero of initial perometry prior to initiation of MLD to the end of the study period. Notations as in A.

reassessment performed at the completion of the third week revealed a volume of $7344 \mathrm{ml}$ for the left lower extremity and a volume of $7214 \mathrm{ml}$ for the right lower extremity. This represented a percent volume loss in the legs of 14.5 and $15 \%$, respectively (Figure 3 ).

The fourth week of treatment consisted of MLD and HIVAMAT for the right upper extremity. The fifth and sixth week of treatment resumed MLD and HIVAMAT, and compression bandaging of the right lower extremity, with the patient continuing use of the compression garment on the left lower extremity during waking hours.

At the conclusion of the six weeks of treatment, the patient was instructed in a home maintenance program of self-MLD, skin care, compression garments for bilateral lower extremities worn during waking hours and continued exercise. The patient continued her selenium. The patient followed up for reassessment one month later. During the one month reassessment with the physical therapist the upper extremities were not measured. The lower extremity volume on the left decreased to $7333 \mathrm{ml}$, and the right to $7278 \mathrm{ml}$, maintaining a $14 \%$ reduction in volume as compared to the initial evaluation (Figure $3)$.

During the study period, the patient's weight was measured and showed a steady decline over the course of treatment (Figure 3). The correlation between weight vs. average leg volumes over time was significant at $r=0.96(\mathrm{P}<0.0001)$, but was not significant for average arm volume over time at $\mathrm{r}=0.61(\mathrm{p}=0.052)$.

On the follow-up appointment with the physician one month after initiation of physical therapy, the patient was visually confirmed to have lost fluid in each leg by physical exam and the fluid pockets in the skin appeared diminished. She denied that her buttocks or abdomen were getting bigger with compression of the lower legs only. The patient continued weight training. The patient was encouraged to continue selenium and to start taking Butcher's broom, which she began at that time (Figure 3) and completed for 93 days prior to the end of study (day 293). Butcher's Broom (Ruscus aculeatus L.) is a natural herbal supplement widely available at organic food stores and is one of very few drugs and supplements to have been shown to improve lymph flow $[29,30]$.

As prescribed by the physician, the patient decreased the use of pioglitazone due to hemoglobin A1C improvement into the normal range, and because of the risk of fluid retention and adipose tissue growth induced by this drug, finally stopping pioglitazone completely 172 days prior to the end of the study period (Figure 3 ).

Five months post physical therapy the patient injured her foot requiring placement of a boot to the knee; she did not exercise for the following 8 weeks. She subsequently had cataract surgery and was similarly immobilized for another 6 weeks (total of 46 days prior to end of study; Figure 3). The patient returned for perometry of her limbs for a six-month reassessment, and the results were striking. While on Bucher's broom and selenium, without physical therapy, the patient continued to lose volume in her limbs. During the time period between the three-month reassessment and the six-month reassessment, in the absence of physical therapy, the patient had a $445 \mathrm{ml}$ reduction in left upper extremity volume, and a $191 \mathrm{ml}$ reduction in right upper extremity volume. The patient also had a $261 \mathrm{ml}$ reduction in left lower extremity volume, and a $72 \mathrm{ml}$ reduction in right lower extremity volume (Figure 3).

The total volume lost over the entire case study period (during which selenium was taken) for the left upper, left lower, right upper and right lower extremities, respectively, was $525 \mathrm{ml}, 1769 \mathrm{ml}, 225 \mathrm{ml}$, and $1614 \mathrm{ml}$. The percent volume reduction during the time period when physical therapy was performed for the left and right lower extremities was $71.3 \%$ and $75.1 \%$ of the total volume, respectively. The percent volume reduction in the lower extremities after stopping pioglitazone was $14.7 \%$ left and $4.4 \%$ right. The percent volume reduction after initiating Butcher's broom was $29.4 \%$ and $21 \%$, respectively.

\section{Discussion}

Thisretrospectivecasereportdescribeshowselenium, in combination with Butcher's broom, helped maintain limb volume reduction after $\mathrm{CDT}$ in a patient with stage II lipedema and lipolymphedema. The 
patient lost on average a total of $1262 \mathrm{ml}$ of fluid per leg after the last treatment session. Selenium, which was taken throughout the treatment period, has been shown to reduce lymphedema $[27,28]$ while the oral supplement, Butcher's broom extract, started 93 days prior to her last session of physical therapy contains ruscogenins which are known to promote lymphatic flow $[29,30]$. For the last 46 days that we followed the patient by perometry, in the absence of physical therapy or exercise due to a foot injury, the patient surprisingly did not gain limb volume and in fact lost an additional $166 \mathrm{ml}$ of volume on average in her legs. The leg volume reduction over the entire study period may have been a synergistic combination between physical therapy, selenium, Butcher's broom, and exercise. Surprisingly, Butcher's broom and selenium were able to maintain limb volume reduction in the absence of MLD and exercise. Thigh-high compression garments were worn on the legs on almost a daily basis, which may have helped to maintain the volume reduction in the legs; however, this had not changed over the course of the study.

The thiazolidinedione, pioglitazone, was stopped 172 days prior to the end of the study period. This is notable as this drug is known to cause fluid retention and decrease visceral adipose tissue while increasing peripheral (including subcutaneous) adipose tissue. It also decreases inflammation as measured by the lowering of C-reactive protein (CRP) $[25,26,31]$. An expectation was that there would be a steep volume loss over the next few months after stopping pioglitazone, but interestingly, the leg volume decreased $<15 \%$ of the total volume reduction. The patient's arms actually increased in volume after stopping pioglitazone, which argues against discontinuation of this drug leading to global fluid loss. In fact, the arms decreased an average of only $37 \mathrm{ml}$ after discontinuation of pioglitazone as measured at the end of our case study. One caveat is that there were only two perometry measurements after discontinuation of pioglitazone, one that showed an increase of volume in the arms and one that showed a mild decrease. An example of the amount of body weight increase after initiation of pioglitazone was demonstrated in patients with fatty liver, where body weight increased approximately $3 \mathrm{~kg}$. In these same patients, whole body fat measured by dual X-ray absorptiometry scan also increased about $3 \mathrm{~kg}$. Interestingly, total body water was not altered significantly after pioglitazone and muscle hydration and extracellular water were unchanged [32]. This case study demonstrated a total decrease of 3.6 $\mathrm{kg}$ in weight over the entire study period and $0.45 \mathrm{~kg}$ after stopping pioglitazone, but also soon after initiating Butcher's broom. Additional measures by perometry during this time would have been helpful to better assess the effect on volume of initiation of Butcher's broom and discontinuation of pioglitazone.

The patient in this case study did not tolerate compression bandaging of her arms secondary to pain, therefore limiting treatment of MLD with HIVAMAT for the duration of one week per arm. However, over a period of 50 days following treatment, she progressively decreased in arm tissue volume while taking selenium and exercising. In addition to the synergistic effect of Butcher's broom, selenium and discontinuation of pioglitazone as explanations for promoting tissue volume loss in the arms after physical therapy was completed, it may be that loss of fluid volume from the legs and may have promoted overall body loss of fluid, which was reflected in the volume loss in the arms.

Interestingly, the left arm of our patient had greater volume than the right and the left cubital area was enlarged compared to the right (physical exam; Figure 3); we note an enlargement in the left cubital area compared to the right in many of our patients (about $1 \mathrm{~cm}$ difference). The cubital area contains lymph nodes and is one site on the body we assess for lipedema fat. All lymph fluid from the body drains into the left thoracic duct except for the right side of the head, neck, and thorax, and right upper extremity, the right lung, right side of the heart, and the convex surface of the liver which drains into the right thoracic duct; both ducts open into the angle of union of the internal jugular and subclavian veins on left and right sides, respectively [33]. While volumes of one arm versus another can vary by a few $100 \mathrm{ml}$, if we agree with Levick and Michel that the majority of interstitial fluid is returned to the blood vasculature through the lymphatic system (and not reabsorbed downstream in micro-vessels) [34], then it would not be unexpected to see a greater backup of fluid on the left side of the body in lipedema, which can be clinically assessed by a larger left cubital area.

The mechanisms underlying the improvement in lipedema in this patient by selenium may be due to its anti-inflammatory properties [35]. Selenium is known to inhibit the matrix remodeling enzyme, matrix metalloproteinase (MMP)-2, and also decreases the MMP inhibitor of MMPs (TIMP)-1 [36]. Selenium decreased edema in two placebo controlled trials for post-mastectomy, as well as head and neck radiation-induced lymphedema [37,38]. Selenium has been shown to increase the efficacy of physical therapy for lymphedema while reducing the incidence of erysipelas infections in patients with chronic lymphedema [37]. It also lowers oxygen radical production in part by increasing glutathione peroxidase and thioredoxin reductase [39]. Immune cells are directly impacted by selenium use as it decreases glycoprotein adhesion molecules (e.g., P-selectin, intercellular adhesion molecule-1, vascular cell adhesion molecule-1, endothelial leukocyte adhesion molecule-1) in a dose-dependent manner [40] that may decongest lymphatic capillaries. It is also important to note that it significantly enhanced cellular immunologic reactions improving efficacy of cytotoxic T-lymphocytes and stimulating macrophages degradation of excess tissue proteins [41]. The US National Research Council has defined the individual maximum safe dietary intake for selenium as $600 \mathrm{mcg}$ daily and the no adverse effect level as $800 \mathrm{mcg}$ daily [42]

The mechanism whereby Butcher's broom may decrease lymphedema is through direct improvement of lymphatic flow [30,31]. Marcelon et al. have shown that the Butcher's Broom affects lymphatic smooth muscle inducement of lymphatic flow through binding to alpha receptors, similar to alpha agonists [43]. The ruscogenins from Ruscus aculeatus $L$. also exhibit remarkable anti-elastase activity by competitive inhibition. The inhibitory effects of this plant's constituents on the activity of elastase, an enzyme system involved in the turnover of the main components of the perivascular amorphous substance, allows it to prevent hydrolysis of both the components of the extracellular matrix (elastin, collagen, proteoglycans) and the endothelial cell membrane adherence proteins [44], therefore ruscogenins are claimed to be effective for the treatment and/or prevention of venous insufficiency.

CDT only treats the edema or fluid component of lipedema and not the excess lipedema tissue. Methods to reduce lipedema adipose tissue include local tumescent liposuction techniques, which have been shown to be effective [45-47]. Longer term studies would be needed to determine if selenium or Butcher's broom had any effect on the adipose tissue component of lipedema.

While this retrospective case report outlines treatment modalities for a single patient with lipedema, it has been estimated that $11-39 \%$ of the female population is affected with lipedema $[9,10]$. If these data are valid, using a prevalence of $11 \%$, and estimating the population in the United States to be $313,914,040,50.8 \%$ of which are women $(159,468,332)$, and if children under the age of five $(6.5 \%)$ are excluded 
then $16,401,318$ women in the US may have lipedema. Termed lipoedema ("fluid in the fat") in the United Kingdom (UK), similar estimates can be made where 15,957,700 women in the UK could also be affected by lipedema. These numbers are staggering and may be higher, suggesting that lipedema is a common disorder. The authors have observed many women with lipedema in the clinic we support continued research into this under recognized disorder [48].

In summary, the ability of Butcher's broom to improve lymphatic flow and selenium's anti-inflammatory properties may be useful in the treatment of lipedema and lipo-lymphedema when combined with standard of care physical therapy which includes MLD with a consideration of HIVAMAT, compression bandaging, compression garments, and exercise. Randomized controlled trials of Butcher's broom and selenium may provide information on their ability to improve lipedema independent of one another. Caution should be used when thiazolidinediones are used for the treatment of metabolic syndrome or diabetes in people with lipedema as they induce fluid retention and subcutaneous adipose tissue accumulation.

\section{References}

1. Wold LE, Hines EA, Allen EV (1951) Lipedema of the legs; a syndrome characterized by fat legs and edema. Ann Intern Med 34: 1243-1250.

2. Allen EV, Hines EAJ (1940) Lipedema of the legs: A syndrome characterised by fat legs and orthostatic edema. Proc Staff Meet Mayo Clin 15: 184-187.

3. Spiller WG (1898) Clinical Memoranda: Report of three cases of adiposis dolorosa. Medical News: 268-270.

4. Collins J (1895) Adiposis dolorosa. In Textbook of Nervous Diseases (FX Dercum Edn)Lea Brothers \& Co 898-200.

5. Cornely ME (2006) Lipedema and Lymphatic Edema. In Liposuction (MA Shiffman Edn) A Di Giuseppe, Berlin Heidelberg: Springer 10-14

6. Földi E (2009) Facts about lipoedema and lymph/lipoedema. In Lymph/ lipoedema treatment in its different approaches. 1st Jobst ${ }^{\circ}$ Scientific Symposium (B-J GmbH Edn) Swindon, Wiltshire SN3 4FH: WACE Corporate Print Limited 36-40.

7. Amann-Vesti BR, Franzeck UK, Bollinger A (2001) Microlymphatic aneurysms in patients with lipedema. Lymphology 34: 170-175.

8. Brorson $\mathrm{H}$ (2012) From lymph to fat: liposuction as a treatment for complete reduction of lymphedema. Int J Low Extrem Wounds 11: 10-19.

9. Beninson J, Edelglass JW (1984) Lipedema--the non-lymphatic masquerader. Angiology 35: 506-510.

10. Foldi E, Foldi M (2006) Lipedema. In Foldi's Textbook of Lymphology (M Foldi, E Foldi Edn) Munich, germany: Elsevier GmbH 417-427.

11. Marshall M, Schwahn-Schreiber C (2011) Prevalence of lipoedema in professional women in Germany (Lipoedema-3-study) Phlebologie 40: 127134.

12. Fife CE, Maus EA, Carter MJ (2010) Lipedema: a frequently misdiagnosed and misunderstood fatty deposition syndrome. Adv Skin Wound Care 23: 8192.

13. Phlebologie LdDGf (2010) Lipödem, Leitlinien der Deutschen Gesellschaft für Phlebologie (DPG).

14. Pascucci A, Lynch PJ (2010) Lipedema with multiple lipomas. Dermatol Online J 16: 4.

15. Child AH, Gordon KD, Sharpe P, Brice G, Ostergaard P, et al. (2010) Lipedema: an inherited condition. Am J Med Genet A 152A: 970-976.

16. Meier-Vollrath I, Schneider W, Schmeller W (2007) Das Lipödem: neue Möglichkeiten der Therapie. Schweiz Med Forum 7: 150-155.

17. Beninson J, Edelglass JW (1984) Lipedema--the non-lymphatic masquerader. Angiology 35: 506-510.

18. Reich-Schupke S, Altmeyer P, Stücker M (2013) Thick legs - not always lipedema. J Dtsch Dermatol Ges 11: 225-233.
19. Deri G, Weissleder H (1997) Vergleichende prä- und posttherapeutische Volumenmessungen in Beinsegmenten beim Lipödem. LymphForsch 1: 3537.

20. Brenke R, Siems W, Obendorfer H (2001) Klinische Erfolge der Komplexen Physikalischen Entstauungstherapie beim Lipödem (Lipödem und andere Erkrankungen des Fettgewebes, Edn) Se RHK, Cologne: Viavital 215-217.

21. Tan CW, Coutts F, Bulley C (2013) Measurement of lower limb volume: Agreement between the vertically oriented perometer and a tape measure method. Physiotherapy

22. Gasbarro V, Bartoletti R, Tsolaki E, Sileno S, Agnati M, Coen M, Conti M, Bertaccini C (2006) Role of HIVAMAT ${ }^{2} 200$ in the treatment for lymphoedema of the limbs. Publication La medicina estetica 30: 373-478.

23. Jahr S, Schoppe B, Reisshauer A (2008) Effect of treatment with low-intensity and extremely low-frequency electrostatic fields (Deep Oscillation) on breast tissue and pain in patients with secondary breast lymphoedema. J Rehabil Med 40: 645-650.

24. Trybulski R (2008) Using the HIVAMAT-200 system in the treatment of wounds. Rehabilitacia W Praktyce 1: 28-33.

25. BeÅ,towski J, Rachå̊, ,czyk J, WA,odarczyk M (2013) Thiazolidinedioneinduced fluid retention: recent insights into the molecular mechanisms. PPAR Res 2013: 628628.

26. Elasy TA, Griffin M (2004) Thiazolidinedione use, fluid retention, and congestive heart failure: a consensus statement from the American Heart Association and American Diabetes Association: response to Nesto. Diabetes Care 27: 2096.

27. Kasseroller R (1998) Sodium selenite as prophylaxis against erysipelas in secondary lymphedema. Anticancer Res 18: 2227-2230.

28. Bruns F, Büntzel J, Mücke R, Schönekaes K, Kisters K, et al. (2004) Selenium in the treatment of head and neck lymphedema. Med Princ Pract 13: 185-190.

29. Behar A (1988) A pharmaco-clinical validation of methods, protocols, results and applications: Cyclo3. Phlebology 3 [suppl. 1]: 113.

30. Rudofsky G (1991) Efficacy of Ruscus extract in venolymphatic edema using foot volumetry. In Return Circulation and Norepinephrine: An Update, (PM Vanhoute Edn) Paris, France: John Libbey Eurotext 121-130.

31. Kavanagh K, Brown KK, Berquist ML, Zhang L, Wagner JD (2010) Fluid compartmental shifts with efficacious pioglitazone therapy in overweigh monkeys: implications for peroxisome proliferator-activated receptor-gamma agonist use in prediabetes. Metabolism 59: 914-920.

32. Balas B, Belfort R, Harrison SA, Darland C, Finch J, et al. (2007) Pioglitazone treatment increases whole body fat but not total body water in patients with non-alcoholic steatohepatitis. J Hepatol 47: 565-570.

33. Gray H (1918) Anatomy of the Human Body. Philadelphia: Lea \& Febiger

34. Levick JR, Michel CC (2010) Microvascular fluid exchange and the revised Starling principle. Cardiovasc Res 87: 198-210.

35. Micke O, Bruns F, Mücke R, Schäfer U, Glatzel M, et al. (2003) Selenium in the treatment of radiation-associated secondary lymphedema. Int J Radiat Oncol Biol Phys 56: 40-49.

36. Conley SM, Bruhn RL, Morgan PV, Stamer WD (2004) Selenium's effects on MMP-2 and TIMP-1 secretion by human trabecular meshwork cells. Invest Ophthalmol Vis Sci 45: 473-479.

37. Micke O, Bruns F, Schäfer U, Kisters K, Hesselmann S, et al. (2000) Selenium in the treatment of acute and chronic lymphedema. Trace Elements and Electrolytes 17: 206-209.

38. Kasseroller RG, Schrauzer GN (2000) Treatment of secondary lymphedema of the arm with physical decongestive therapy and sodium selenite: a review. Am J Ther 7: 273-279.

39. Lewin MH, Arthur JR, Riemersma RA, Nicol F, Walker SW, et al. (2002) Selenium supplementation acting through the induction of thioredoxin reductase and glutathione peroxidase protects the human endothelial cell line EAhy926 from damage by lipid hydroperoxides. Biochim Biophys Acta 1593: 85-92.

40. Horváthová M, Jahnová E, Gazdík F (1999) Effect of selenium supplementation in asthmatic subjects on the expression of endothelial cell adhesion molecules in culture. Biol Trace Elem Res 69: 15-26. 
Citation: Nourollahi S, Mondry TE, Herbst KL (2013) Bucher's Broom and Selenium Improve Lipedema: A Retrospective Case Study. Altern Integ Med 2: 119. doi:10.4172/2327-5162.1000119

Page 7 of 7

41. Kiremidjian-Schumacher L, Roy M, Glickman R, Schneider K, Rothstein S, et al. (2000) Selenium and immunocompetence in patients with head and neck cancer. Biol Trace Elem Res 73: 97-111.

42. (1983) Selenium in nutrition: revised, National Research Council, Washington, D.C.

43. Marcelon G, Pouget G, Tisné-Versailles J (1988) Effect of ruscus on the adrenoreceptors of the canine lymphatic thoracic duct. Phlebology 3[suppl. 1]: 109-112.

44. Facino RM, Carini M, Stefani R, Aldini G, Saibene L (1995) Anti-elastase and anti-hyaluronidase activities of saponins and sapogenins from Hedera helix, Aesculus hippocastanum, and Ruscus aculeatus: factors contributing to their efficacy in the treatment of venous insufficiency. Arch Pharm (Weinheim) 328 720-724.

45. Rapprich S, Dingler A, Podda M (2011) Liposuction is an effective treatment for lipedema-results of a study with 25 patients. J Dtsch Dermatol Ges 9: 33-40.

46. Stutz JJ, Krahl D (2009) Water jet-assisted liposuction for patients with lipoedema: histologic and immunohistologic analysis of the aspirates of 30 lipoedema patients. Aesthetic Plast Surg 33: 153-162.

47. Peled AW, Slavin SA, Brorson H (2012) Long-term Outcome After Surgical Treatment of Lipedema. Ann Plast Surg 68: 303-307.

48. Herbst KL (2012) Rare adipose disorders (RADs) masquerading as obesity Acta Pharmacol Sin 33: 155-172. 